Early Childhood Research Quarterly, 4, 317-330 (1989)

\title{
Temperament Ratings by Parents of Preterm and Full-Term Infants
}

\author{
James W. Plunkett \\ The University of Michigan \\ David R. Cross \\ Texas Christian University \\ Samuel J. Meisels \\ The University of Michigan
}

This study investigated temperament ratings among three groups of preterm infants, differing by degree of risk status, and a full-term group. Pairs of mothers and fathers completed the Rothbart Infant Behavior Questionnaire (IBQ) when their infants were 12 or 18 months of age. Findings concerning the internal consistencies across the three preterm (PT) groups demonstrated that both PT mothers and fathers found the IBQ temperament dimensions to be coherent constructs, regardless of initial severity and chronicity of their infants' illness. Preterm mothers and fathers showed some differences in their ratings: Median correlation of their scales was .46; and PT mothers rated their infants as more active $(p<.002)$ and soothable $(p<.06)$ than did PT fathers. Although there was only one significant difference between PT and FT mothers' ratings, within-group differences among the preterms emerged. The absence of stronger patterns of differences between PT and FT groups and between high-risk and low-risk preterm groups is discussed.

Infant temperament - a construct used to describe individual differences in the behavior of young children-is receiving extensive attention in the research literature (Campos, Barrett, Lamb, Goldsmith, \& Stenberg, 1983;

This investigation was supported in part by a faculty research award from the Horace Rackham School of Graduate Studies at the University of Michigan and by a grant from the March of Dimes Birth Defects Foundation. The findings were presented at the International Conference on Infant Studies, Los Angeles, California, April 1986. We wish to acknowledge the important contributions of Dietrich Roloff, Patricia Pasick, Gilbert Stiefel, Karen Mikus, and Ellen Wolock. We also wish to thank the parents and children who participated in this study.

Correspondence and requests for reprints should be sent to James W. Plunkett, University Center for the Child and Family, The University of Michigan, 1007 E. Huron, Ann Arbor, MI 48109. 
Goldsmith \& Campos, 1982). Definitions of temperament abound, and several methodologies exist for measuring it (Bates, Freeland, \& Lounsbury, 1979; Carey \& McDevitt, 1978; Plomin \& Rowe, 1979). Two of the approaches to defining and operationalizing temperament differ in the emphasis placed on behavioral style and behavioral content. One of the best-known theories of temperament, derived from the New York Longitudinal Study (Thomas \& Chess, 1977; Thomas, Chess, \& Birch, 1968), emphasizes behavioral style. This approach has been incorporated into the Infant Temperament Questionnaire (ITQ), developed by Carey and his colleagues (Carey, 1970; 1972; Carey, Fox, \& McDevitt, 1977; Carey \& McDevitt, 1978). Rothbart (1981) and Rothbart and Derryberry (1981) have proposed a contrasting temperament theory that focuses on discrete emotions and affective dimensions. Rothbart developed the Infant Behavior Questionnaire (IBQ), which isolates specific affective dimensions such as activity level, distress to limitations, fear, duration of orienting, smiling and laughter, and soothability.

Both of these approaches have been used in studies with different samples, including infants with Down syndrome (Rothbart \& Hansen, 1983) and other high-risk populations (Hubert, Wachs, Peters-Martin, \& Gandour, 1982; Sostek \& Anders, 1977). However, there is little standardization information about how temperament constructs developed on normative samples of healthy, full-term infants apply to and differentiate atypical populations at developmental risk. Furthermore, very little has been reported on fathers' perceptions of infant temperament, especially fathers of high-risk and handicapped infants.

Premature infants as a group constitute an important sample on which to focus temperament studies. The biological immaturity and vulnerability of the premature infant in the first months of life contribute to a less optimal ability to modulate arousal, attend to social stimuli, and maintain state organization (Als, Lester, \& Brazelton, 1979; DiVitto \& Goldberg, 1979; Field, 1978, 1983; Sigman, 1983). Consequently, premature infants have been found to be more difficult social partners during the early months of life. They have also been seen as fussier, less responsive, more difficult to engage, and less satisfying to their parents than healthy, full-term infants (Brown \& Bakeman, 1980; Field, 1978; Goldberg, 1978). The increased risk of deviant patterns of later social interaction has been attributable in part to the parenting challenges posed by these less stable, less predictable, and more difficult infants. In short, preterm infants appear to display important temperamental qualities that may differentiate them from healthy, full-term infants.

Nevertheless, few studies have investigated the presence of preterm/fullterm temperamental differences beyond the first months of life (Field, 1978; Field \& Greenberg, 1982; Medoff-Cooper, 1986; Oberklaid, Prior, Nolan, Smith, \& Flavell, 1985; Oberklaid, Prior, \& Sanson, 1986; Roth, Eisenberg, 
\& Sell, 1984; Washington, Minde, \& Goldberg, 1986). Field $(1978,1983)$, using the ITQ, found that infants with respiratory distress syndrome (RDS) had more difficult temperaments at 4 and 8 months of age than their fullterm counterparts. Medoff-Cooper (1986) and Washington et al. (1986), in samples of infants with birth weights of less than $1,500 \mathrm{gms}$, also reported differences on the ITQ in the first years of life. However, both studies showed preterm/full-term differences to be greatly attenuated or eliminated by 12 months of age.

Studies of less compromised, lower risk preterm samples have demonstrated no preterm/full-term differences. Oberklaid et al. $(1985,1986)$ failed to find temperament differences between a heterogeneous, relatively healthy group of preterms and full-term infants at 4 and 8 months of age. Roth et al. (1984) also failed to observe differences in temperament ratings of 12month-old full-terms and preterms with a mean birth weight of 1,600 gms.

This study reports on an investigation of temperament in the second year of life among four groups of infants: Three groups of premature infants differing in severity and chronicity of postnatal respiratory illness and a full-term contrast group of healthy infants. Four questions are addressed: First, are the meanings of temperament constructs for mothers and fathers of preterm infants similar to those of parents of healthy, full-term infants? Second, are mothers' and fathers' perceptions of temperament in agreement with one another? Third, are there preterm/full-term temperamental differences in the second year of life? Fourth, among preterm infants, is the severity and chronicity of biological risk associated with different qualities of infant temperament?

\section{METHODS}

\section{Subjects}

This study included 51 preterm (PT) infants and 20 full-term (FT) infants from intact families. The PT infants all weighed less than 2,501 gms at birth and had gestational ages of less than 37 weeks, as established by Ballard score (Ballard, Novak, \& Driver, 1979). The PT infants were enrolled after a review of case records of consecutive admissions to the University of Michigan Hospitals between September 1980 and August 1982. Of the 82 PT families contacted, $79 \%$ agreed to participate in the research. In all, 65 PT infants were evaluated. However, 3 were later dropped from the sample because of procedural errors and incorrect initial selection criteria, and 10 were not included because they came from divorced families where only one parent was available to complete the Temperament Questionnaire. The FT sample was self-selected; it was obtained by advertising in the community. All families signed consent forms and were reimbursed for the cost of travel and expenses. 
The PT infants represented a range of risk status based on the chronicity and severity of postnatal respiratory illness. Chronicity was defined as the length of time from birth until respiratory problems were resolved, which was determined by radiographic evidence. Severity was conceptualized as the length of initial hospitalization primarily because of the chronicity of the respiratory illness, rather than other complications. Three risk groups were constructed in accordance with the following criteria: (a) high risk (HRPT; $n=14$ ), composed of infants with respiratory illness unresolved within 3 weeks and hospitalizations of longer than 2 months; (b) moderate risk (MR-PT; $n=19$ ), composed of infants with respiratory illness resolved within 3 weeks and hospitalizations of 1 to 2 months; and (c) low risk (LRPT; $n=18$ ), composed of healthy preterm infants who had no respiratory illness and hospitalizations of less than 1 month. The mean hospitalization of the HR-PT group was 88.4 days $(S D=18.6$; range $=62-121)$; for the MRPT group it was 37.3 days $(S D=8.3$; range $=27-54)$; and for the LR-PT group it was 10.5 days $(S D=6.5$; range $=2-24)$. Within the HR-PT group 10 infants had bronchopulmonary dysplasia (BPD), 2 had chronic pulmonary insufficiency of prematurity (CPIP), and 2 had respiratory distress syndrome (RDS). Within the MR-PT group there were 15 infants with RDS and 4 with BPD. The range of chronicity and severity incorporated into this sample increases the relevance of the study's conclusions for a large proportion of the preterm population.

To better assess the effect of respiratory illness, infants were excluded who had one or more of the following conditions: central nervous system, neuromuscular, or sensory disorders; hydrocephalus; intraventricular hemorrhage > Grade II; retrolental fibroplasia; Down syndrome; cleft palate; severe metabolic disorders; extreme hyperbilirubinemia; intrauterine growth failure; or a primary medical complication other than respiratory illness accounting for prolonged hospital stay. In addition, mothers were not included who had a history of drug or alcohol addiction during pregnancy, severe mental disorder, or age of less than 17 years at the time of the child's birth. All infants had been living with the primary caregiver from birth to the time of the evaluation.

Full-term birth was defined as a birth weight (BW) of $3,316.8 \mathrm{gms}$ ( $S D=$ 294.1) and a gestational age of 38 to 42 weeks. Full-term infants' postbirth hospitalization was less than 1 week, and all were healthy with no complications. The mean $\mathrm{BW}$ was $3,345.4 \mathrm{gms}(S D=257.3)$ and the mean gestational age (GA) was 40.2 weeks $(S D=1.0)$.

There were significant differences among the three PT groups on BW and GA. The mean BWs were: $\mathrm{HR}-\mathrm{PT}=1,246.4 \mathrm{gms}(S D=544.9)$; $\mathrm{MR}-\mathrm{PT}=$ $1,603.8 \mathrm{gms}(S D=251.1) ; \mathrm{LR}-\mathrm{PT}=2,169.8 \mathrm{gms}(S D=242.6) ; F(2,48)=28.1$, $p<.0001$. The mean GAs were: HR-PT $=29.6$ weeks $(S D=2.4)$; MR$\mathrm{PT}=32.0$ weeks $(S D=1.6) ; \mathrm{LR}-\mathrm{PT}=33.9$ weeks $(S D=1.9) ; F(2,48)=18.8$, $p<.0001$. 
There were no significant differences among the groups with respect to sex of child, parity, socioeconomic status (SES), and maternal and paternal ages at infant's birth. Across all four groups $59 \%$ of the infants were male, $62 \%$ firstborn, and $38 \%$ from low-SES families (i.e., Classes IV and V of the Hollingshead Four-Factor Index). Mean maternal age was 26.8 years ( $S D=$ 5.4) and mean paternal age was 28.7 years $(S D=7.7)$.

\section{Age Stratification of Sample}

Subjects were evaluated at one of two time points: 12 months $(n=37)$ or 18 months $(n=34)$ time post-hospital discharge (TPD). To focus the study on the development of infant-caregiver relationships, TPD was chosen as a time point for assessment rather than chronological age corrected or uncorrected for gestational age. In this way, even though the preterm risk groups differed by length of hospitalization, all subjects-preterm and full-termwere provided with comparable lengths of time to experience the primary caregiving environment. All threc risk groups and the full-term group were equally represented at each of the age points. Furthermore, there were no significant differences in the distributions between the 12- and the 18-month age groups on sex, parity, family configuration, SES, or maternal education.

\section{Procedures}

Mothers and fathers independently completed the Rothbart Infant Behavior Questionnaire (IBQ), which consists of 94 items rated on 7-point scales $(1=$ never present to $7=$ always present $)$. Summary scales were formed according to Rothbart's (1981) procedures that define six dimensions of infant behavior:

1. Activity level, that is, child's gross motor activity.

2. Smiling and laughter, as manifested in any situation.

3. Fear, that is, the child's distress or latency to approach an intense or novel stimulus.

4. Soothability, that is, reduction of fussing, crying, or distress when soothing techniques are used.

5. Distress to limitations, that is, child's fussing, crying, or showing distress while waiting, being confined, or experiencing delayed gratification.

6. Duration of orienting, that is, child's degree of focus on a single object for extended periods of time.

\section{RESULTS}

The results will be presented in three parts, focusing initially on the psychometric properties of the Rothbart scales among preterm mothers (PTM) and preterm fathers (PTF). First, Cronbach alphas are presented in order to demonstrate the strength of the internal consistency of the PTMs' and PTFs' 
Table 1. Coefficient Alphas for IBQ Scales: Mothers

\begin{tabular}{lcccccc}
\hline IBQ Scale & $\begin{array}{c}\text { 12 Months } \\
(n=\mathbf{3 7})\end{array}$ & $\begin{array}{c}\text { 18 Months } \\
(n=\mathbf{3 4})\end{array}$ & $\begin{array}{c}\text { High Risk } \\
(n=\mathbf{1 4})\end{array}$ & $\begin{array}{c}\text { Moderate Risk } \\
(n=19)\end{array}$ & $\begin{array}{c}\text { Low Risk } \\
(n=\mathbf{1 8})\end{array}$ & $\begin{array}{c}\text { 12-Month } \\
\text { Rothbart } \\
\text { Norms }\end{array}$ \\
\hline Activity & .80 & .84 & .78 & .73 & .83 & .84 \\
Distress & .82 & .76 & .82 & .75 & .77 & .78 \\
Fear & .70 & .77 & .71 & .77 & .81 & .81 \\
Orienting & .56 & .79 & .73 & .62 & .77 & .72 \\
Smiling & .79 & .61 & .81 & .58 & .72 & .80 \\
Soothability & .58 & .78 & .72 & .72 & .81 & .82 \\
\hline
\end{tabular}

${ }^{a}$ Rothbart, 1981.

Table 2. Coefficient Alphas for IBQ Scales: Fathers

\begin{tabular}{lccccc}
\hline IBQ Scales & $\begin{array}{c}\text { 12 Months } \\
(n=\mathbf{3 7})\end{array}$ & $\begin{array}{c}\text { 18 Months } \\
(n=\mathbf{3 4})\end{array}$ & $\begin{array}{c}\text { High Risk } \\
(n=14)\end{array}$ & $\begin{array}{c}\text { Moderate Risk } \\
(\boldsymbol{n}=\mathbf{1 9})\end{array}$ & $\begin{array}{c}\text { Low Risk } \\
(\boldsymbol{n}=\mathbf{1 8})\end{array}$ \\
\hline Activity & .82 & .81 & .74 & .74 & .84 \\
Distress & .86 & .66 & .61 & .67 & .93 \\
Fear & .82 & .85 & .81 & .79 & .89 \\
Orienting & .73 & .46 & .70 & .34 & .79 \\
Smiling & .84 & .61 & .81 & .67 & .91 \\
Soothability & .78 & .63 & .78 & .77 & .75 \\
\hline
\end{tabular}

Rothbart scales. Second, the concordance between PTMs' and PTFs' responses is addressed by means of correlations. Finally, two group contrasts are tested: preterm (PT) versus full-term (FT) infants, and low-risk preterm (LR-PT) versus high-risk preterm (HR-PT) infants. The latter comparison was selected to maximize the within-group homogeneity of the preterm contrast.

\section{Internal Consistency}

The internal consistencies of the three PT risk groups' responses to the IBQ were examined to determine whether or not parents of PT infants of differing risk status perceive the constructs of temperament similarly to Rothbart's normative sample. Tables 1 and 2 present the Cronbach alphas for the mothers and fathers across the PT groups and across the two age groups.

As shown in Table 1, the general pattern of results reveals that the scales for the PT mothers show moderate to high internal consistency, with alphas ranging from .61 to .84 (median $=.75$ ). Furthermore, the alphas are similar across age groups, with medians in the mid .70s for both groups. A similar pattern for fathers' scores is observed in Table 2, with alphas ranging from .61 to .91 (median $=.78$ ). The fathers appear to show less internal consistency in the 18-month group (12 months: median $\alpha=.82 ; 18$ months: median 
Table 3. Correlations of Mothers' and Fathers' IBQ Scores Partialling Out Sex, SES, and Age of Assessment

\begin{tabular}{lcccc}
\hline IBQ Scale & $\begin{array}{c}\text { HR-PT } \\
n=14\end{array}$ & $\begin{array}{c}\text { MR-PT } \\
n=19\end{array}$ & $\begin{array}{c}\text { LR-PT } \\
n=18\end{array}$ & $\begin{array}{c}\text { FT } \\
n=20\end{array}$ \\
\hline Activity & .33 & .20 & $.47^{*}$ & .26 \\
Distress & $.83^{* *}$ & $.56^{* *}$ & $.67^{* *}$ & $.72^{* *}$ \\
Fear & $.93^{* *}$ & $.66^{* *}$ & $.75^{* *}$ & $.54^{* *}$ \\
Orienting & $.78^{* *}$ & .21 & .23 & .26 \\
Smiling & .43 & -.05 & .23 & -.15 \\
Soothability & $.59^{*}$ & -.10 & .10 & .19 \\
\hline
\end{tabular}

$* p<.10 . \quad * * p<.01$.

$\alpha=.62$ ). The least internally consistent ratings were given by parents of the MR infants. Nevertheless, these data demonstrate that PT mothers and fathers at 12 and 18 months TPD find Rothbart's temperament dimensions to be coherent constructs for their infants, regardless of the severity and chronicity of their postnatal illness.

\section{Correlations Between Mothers' and Fathers' Scores}

The scores of the PT and FT mothers and fathers were correlated to determine the extent of interparent agreement on ratings of their infants' temperament. The correlations of mothers' and fathers' scores within the three PT groups and the FT group, partialling out infant age, sex, and family SES, are presented in Table 3.

When the correlations across all four groups are considered, the median $r$ is .38 (n.s.), with a range of -.15 to .93 . This overall pattern is a somewhat lower interparent agreement than reported on correlations between scores of FT mothers and a second caregiver (Bates, 1980; Field \& Greenberg, 1982; Goldsmith \& Campos, 1982; Huitt \& Ashton, 1982; Rothbart, 1981). However, interparent agreement differs widely depending on the temperament dimension being considered. Distress to limits and fear both show strongly significant interparent agreement across all four groups (median $r=.69$; range $=.54-.93$ ), whereas there is little significant agreement in the other four dimensions. It is interesting to note that the HR-PT parents show the strongest overall pattern of interparent agreement, demonstrating high concordance on distress, fear, and orienting and moderate agreement on soothability.

\section{Comparisons of Ratings of Preterm and Full-Term Infants}

The means of the mothers' and fathers' temperament ratings for the three preterm groups and the full-term group are presented in Figures 1 and 2. Two sets of planned comparisons were carried out. First, PT parents were compared with the FT parents to test for the presence of effects attributable 


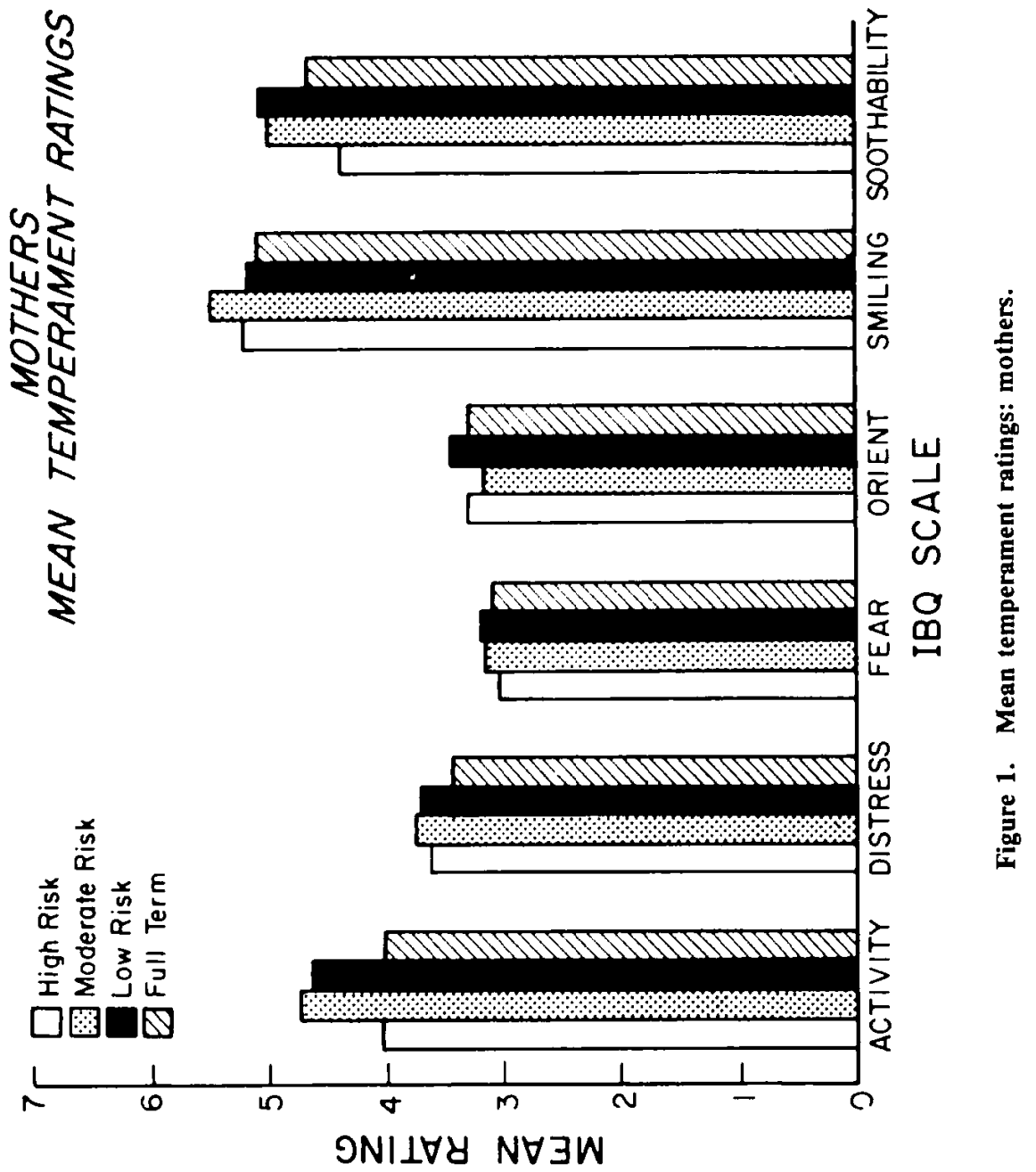




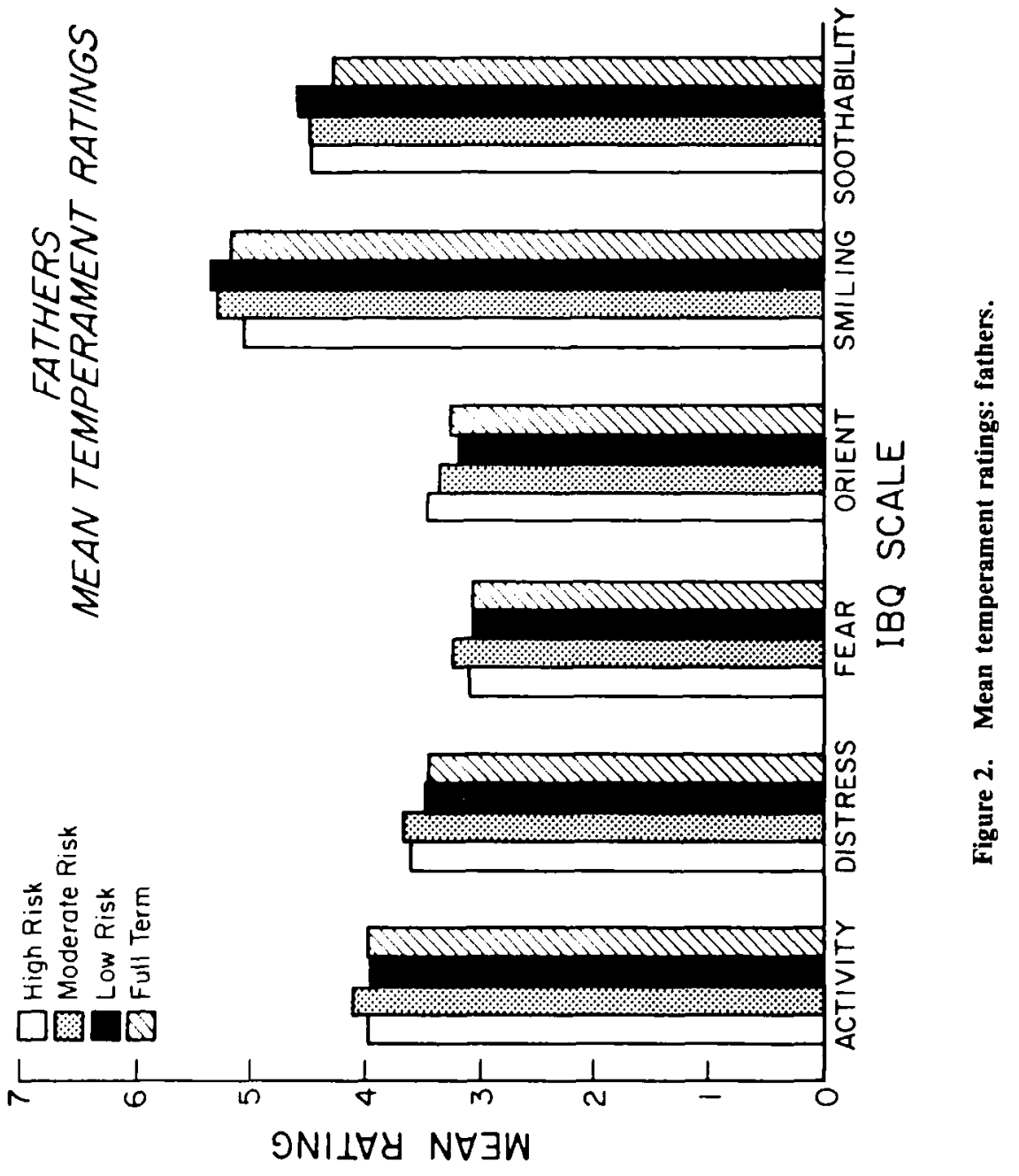


to prematurity per se. Second, within the PT group, HR-PT parents were compared with LR-PT parents to determine if the within-PT group variation is attributable to the severity and chronicity of initial infant health status. For each set of comparisons, two-way ANOVAs (Risk Group $\times$ Age Group) were first performed to rule out interactions with age at testing.

The results of the maternal PT/FT comparisons show no significant interaction effects with age, and a single PT/FT main effect: PT mothers rated their infants as more active than FT mothers, $F(1,69)=4.22, p<.05$. For the fathers, there were neither interaction effects with age nor main effects for the PT/FT comparisons. Thus the data reveal no strong patterns of PT/FT differences for either mothers' or fathers' ratings of temperament.

Next, the temperament ratings of the HR-PT infants were compared with the ratings of the LR-PT infants. On the maternal ratings, there were no interaction effects with age, but there were two main effects for group membership. Compared with the LR-PT mothers, the HR-PT mothers perceived their infants as less soothable, $F(1,30)=4.59, p<.04)$, and less active, $F(1,30)=3.95, p<.05$. Thus, as an examination of the means in Figure 1 shows, the previous conclusion that PT mothers as a group perceived their infants as more active than did FT mothers actually obscures the variability attributable to severity of risk status within the PT group.

On the fathers' scales, there were no significant interactions or main effects for the HR-PT and LR-PT comparisons. Thus, there is no pattern of significant variability within the PT group on the paternal ratings.

Finally, main effects for age, sex, and SES were examined. There were no significant effects for sex, and only one significant SES effect: Low-SES fathers perceived their infants as showing greater duration of orienting than did mid-SES fathers, $F(1,70)=4.61, p<.04$. Also, there were two main effects for age: mothers reported lower orienting scores for 12-month-olds, $F(1,70)=4.27, p<.05$; and fathers perceived 12 -month-olds as more soothable than 18 -month-olds, $F(1,70)=4.30, p<.05$.

\section{DISCUSSION}

Assessment of high-risk, atypical groups is always confronted with the problem of whether the normative measures developed on healthy, full-term subjects are appropriate for assessing the development of non-normative populations (Mott et al. 1986). Solutions to this problem require that the psychometric properties of instruments used with atypical populations be compared with the properties obtained with the normative sample. In this study, the pattern of strong internal consistency of parental ratings across the preterm groups supports the use of the Rothbart IBQ with such atypical populations. In this instance, it is clear that parents of preterm infantsregardless of the severity of infant biological risk - view the temperament 
constructs in a way similar to that of the full-term parents in Rothbart's normative sample.

In this study, the IBQ was used with both a 12- and an 18-month age group, although the measure was originally normed only for infants up to 12 months. The extension of the Rothbart to this age group appears justified. Its use with 18-month-olds has been reported in the literature (Singer, Brodzinski, Ransay, Steir, \& Waters, 1985; Thompson \& Lamb, 1982). Furthermore, the absence of Age $\times$ Group interactions establishes that the relationships among the groups are not affected by age at assessment. Finally, the two main effects for age are both developmentally consistent: For mothers, the 18-month TPD infants are seen as having more prolonged capacity for orienting; and for fathers, infants in the 18-month group were seen as more soothable. This last finding raises the possibility of age-dependent differences in the extent of paternal involvement and of fathers' enhanced sense of efficacy in their parenting of older infants.

Few studies have examined the concordance of parental perceptions of temperament among preterm infants. Correlations of PT parents' ratings demonstrate low to modest concordance (median $r=.38$ ), but there is marked variability in this agreement, depending upon risk status. Parents of the HR infants showed strikingly high concordance (median $r=.68$ ), particularly when compared with the other three groups (median $r s=.20-.35$ ). The one other comparable report about temperament among small, high-risk preterm infants reports a similarly high concordance, using a different temperament measure. Washington et al. (1986) found that the parents of infants with a birth weight of less than $1,500 \mathrm{gms}$ had a correlation of .60 on the Carey ITQ administered at 12 months.

Several factors may account for the greater agreement among parents of sicker, higher risk infants. The agreement may reflect greater involvement on the part of HR parents with both their infant and with each other, thus enabling the HR parents to be more familiar with their infant and with their spouse's experience of the infant. It is also possible that sicker PT infants as a group demonstrate more marked temperament-relevant behaviors that are cross-situationally consistent than lower risk infants. However, further research is necessary to validate these hypotheses.

The virtual absence of PT/FT differences on the IBQ is consistent with most other studies. With the single exception of Field $(1978,1983)$, other researchers have repeatedly failed to identify PT/FT differences on parent report measures beyond 6 months of life (Oberklaid et al., 1985, 1986; Roth et al., 1984; Washington et al., 1986). In fact, the one PT/FT difference in this study concerning maternal rating of activity obscures the variability within the PT sample. The healthy preterm infants have high activity ratings, whereas the HR infants have ratings that are virtually identical to those of the FT infants. This variability within the PT sample is further illu- 
strated by the higher maternal soothability rating of LR compared with HR infants. This finding suggests that, at least for mothers, it is the sickest infants who are the most difficult to comfort, whereas the healthy premature infants may be regarded as excessively active. While both of these dimensions have been identified in other studies of preterms in the early months of life (Brachfeld, Goldberg, \& Sloman, 1980; DiVitto \& Goldberg, 1979; Field, 1977), these data support the view that attributing temperamental qualities to prematurity per se may be misleading because such a position does not take into account the variability within the preterm population.

The absence of stronger patterns of differences between preterm and fullterm groups and between high-risk and low-risk preterm groups suggests several interpretations. First, it is possible that differences in neonatal, biological risk are not strongly associated with persistent patterns of biobehavioral regulation and expression beyond the early months. Second, it is possible that parent report questionnaires are not effective means of describing constitutionally grounded temperamental dimensions (Brachfeld et al., 1980; Vaughn, Taraldson, Crichton, \& Egeland, 1981). But even more likely is the possibility that the identifiable dimensions of temperament are not unitary, constitutional givens that exert predictable influences on behavior. Instead, temperament might best be conceptualized as a set of flexible parameters of responsivity and behavior potential which contributes to and is shaped by interaction with the environment. As such, parent report measures will be inadequate means of capturing meaningful temperamental processes, because parents cannot accurately reconstruct temperamental potentialities or reflect upon the transactional history they have been partners to during the first year (Sroufe, 1985). Thus there may be important differences in responsivity and reactivity associated with high-risk preterm birth, but parent report measures that focus on static traits are unlikely to be a fruitful methodology for identifying them.

\section{REFERENCES}

Als, H., Lester, B.M., \& Brazelton, T.B. (1979). Dynamics of the behavioral organization of the premature infant: A theoretical perspective. In T.M. Field, A.M. Sostek, S. Goldberg, \& H.H. Shuman (Eds.), Infants born at risk (pp. 173-192). New York: Spectrum.

Ballard, J.L., Novak, K.K., \& Driver, M. (1979). A simplified score for assessment of fetal maturation of newly born infants. Pediatrics, 95, 769-774.

Bates, J.E. (1980). The concept of difficult temperament. Merrill-Palmer Quarterly, 26, 300-319.

Bates, J.E., Freeland, C., \& Lounsbury, M.L. (1979). Measurement of infant difficultness. Child Development, 50, 794-803.

Brachfeld, S., Goldberg, S., \& Sloman, J. (1980). Parent-infant interaction in free play at 8 and 12 months: Effccts of prematurity and immaturity. Infant Behavior and Development, 3, 289-305. 
Brown, J.V., \& Bakeman, R. (1980). Relationships of human mothers with their infants during the first year of life: Effect of prematurity. In R.W. Bell \& W.P. Smotherman (Eds.), Maternal influences and early behavior (pp. 353-373). New York: Spectrum.

Campos, J.J., Barrett, K.C., Lamb, M.E., Goldsmith, H.H., \& Stenberg, C. (1983). Socioemotional development. In M.M. Haith \& J.J. Campos (Eds.), Handbook of child psychology (Vol. 2): Infancy and developmental psychobiology. New York: Wiley.

Carey, W.B. (1970). A simplified method of measuring infant temperament. Journal of Pediatrics, 77, 188-194.

Carey, W.B. (1972). Measuring infant temperament. Journal of Pediatrics, 81, 414.

Carey, W.B., Fox, M., \& McDevitt, S. (1977). Temperament as a factor in early school adjustment. Pediatrics, 60, 621-624.

Carey, W.B., \& McDevitt, S. (1978). Revision of the Infant Temperament Questionnaire. Pediatrics, 6I, 735-739.

Daniels, D., Plomin, R., \& Greenhalgh, J. (1984). Correlates of difficult temperament in infancy. Child Development, 55, 1184-1194.

DiVitto, B., \& Goldberg, S. (1979). The effects of newborn medical status on carly parentinfant interaction. In T.M. Field, A.M. Sostek, S. Goldberg, \& H.H. Shuman (Eds.), Infants born at risk: Behavior and development (pp. 311-332). New York: Spectrum.

Field, T. (1977). Effects of early separation, interactive deficits, and experimental manipulations on infant-mother face-to-face interaction. Child Development, 48, 763-771.

Field, T. (1978). The 3 Rs of infant-adult social interactions: Rhythms, repertoires, and responsibility. Journal of Pediatric Psychology, 3, 131-136.

Field, T. (1983). Early interactions and interaction coaching of high-risk infants and parents. In M. Perlmutter (Ed.), The Minnesota symposia on child psychology (Vol. 16). Hillsdale, NJ: Erlbaum.

Field, T., \& Greenberg, R. (1982). Temperament ratings by parents and teachers of infants, toddlers, and preschool children. Child Development, 53, 160-163.

Goldberg, S. (1978). Prematurity: Effects on parent-infant interaction. Journal of Pediatric Psychology, 3, 137-144.

Goldsmith, H.H., \& Campos, J.J. (1982). Toward a theory of infant temperament. In R.N. Emde \& R.J. Harmon (Eds.), The development of attachment and affiliative systems: Psychobiological aspects. New York: Plenum.

Hubert, N.C., Wachs, T.D., Peters-Martin, P., \& Gandour, M.J. (1982). The study of early temperament: Measurement and conceptual issues. Child Development, 53, 571-600.

Huitt, W., \& Ashton, P. (1982). Parents' perception of infant temperament: A psychometric study. Merrill-Palmer Quarterly, 28, 95-109.

Medoff-Cooper, B. (1986). Temperament in very low birth weight infants. Nursing Research, $35,39-143$.

Mott, S.E., Fewell, R.R., Lewis, M., Meisels, S.J., Shonkoff, J.P., \& Simeonsson R. (1986). Methods for assessing child and family outcomes in early childhood special education programs: Some views from the field. Topics in Early Childhood Special Education, 6, $1-15$.

Oberklaid, F., Prior, M., Nolan, T., Smith, P., \& Flavell, H. (1985). Temperament in infants born prematurely. Journal of Developmental and Behavioral Pediatrics, 6, 57-61.

Oberklaid, F., Prior, M., \& Sanson, A. (1986). Temperament of preterm versus full-term infants. Journal of Developmental and Behavioral Pediatrics, 7, 159-162.

Plomin, R., \& Rowe, D. (1979). Genetic and environmental etiology of social behavior in infancy. Developmental Psychology, 15, 62-72.

Roth, K., Eisenberg, N., \& Sell, E.K. (1984). The relation of preterm and full-term infants' temperament to test-taking behaviors and developmental status. Infant Behavior and Development, 7, 495-505.

Rothbart, M.K. (1981). Measurement of temperament in infancy. Child Development, 52, 569-578. 
Rothbart, M.K., \& Derryberry, D. (1981). Development of individual differences in temperament. In M.E. Lamb \& A.L. Brown (Eds.), Advances in developmental psychology (Vol. 1). Hillsdale, NJ: Erlbaum.

Rothbart, M.K., \& Hanson, M.J. (1983). A caregiver report comparison of temperamental characteristics of Down syndrome and normal infants. Developmental Psychology, 19, 766-769.

Sigman, M.D. (1983). Individual differences in infant attention: Relations to birth status and intellience at five years. In T.M. Field \& A.M. Sostek (Eds.), Infants born at risk. New York: Grune \& Stratton.

Singer, L.M., Brodzinski, D.M., Ransay, D., Steir, M, \& Waters, E. (1985). Mother-infant attachment in adoptive families. Child Development, 56, 1543-1551.

Sostek, A.M., \& Anders, T.F. (1977). Relationships among the Brazelton neonatal scale, Bayley infant scales and early temperament. Child Development, 48, 320-323.

Sroufe, L.A. (1985). Attachment classification from the perspective of infant-caregiver relationships and infant temperament. Child Development, 56, 1-14.

Thomas, A., \& Chess, S. (1977). Temperament and development. New York: Brunner/Mazel.

Thomas, A., Chess, S., \& Birch, H.G. (1968). Temperament and behavior disorders in children. New York: New York University Press.

Thompson, R., \& Lamb, M.E. (1982). Stranger sociability and its relationship to temperament and social experience during the second year. Infant Behavior and Development, S, 277-287.

Vaughn, B.E., Taraldson, B.J., Crichton, L., \& Egeland, B. (1981). The assessment of infant temperament: A critique of the Carey Infant Temperament Questionnaire. Infant Behavior and Development, 4, 1-17.

Washington, J., Minde, K., \& Goldberg, S. (1986). Temperament in preterm infants: Style and stability. Journal of the American Academy of Child Psychiatry, 25, 493-502. 